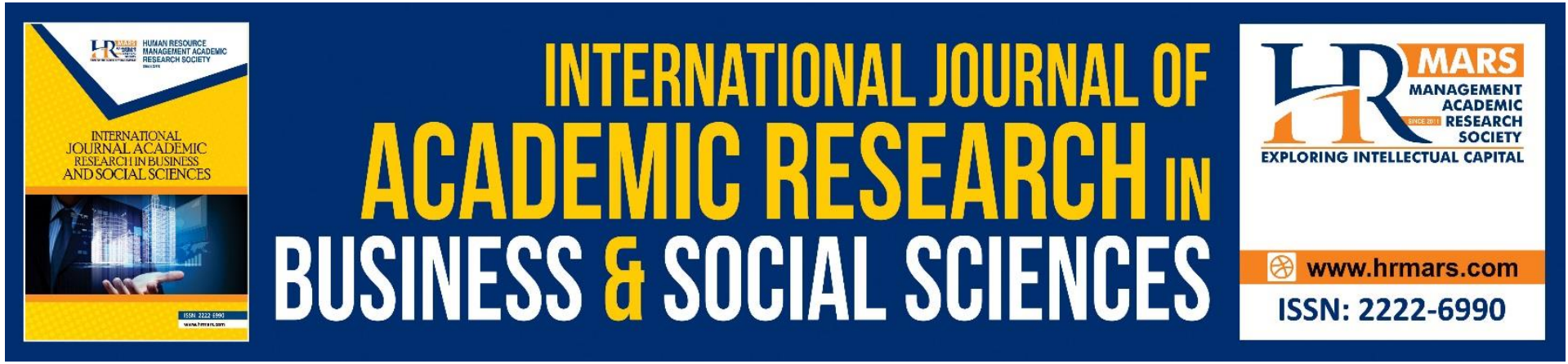

\title{
The Relationship between Emotional Regulation and Depression among Adolescent in Bangladesh
}

Tanni K. T., Zaida Nor Zainudin, Siti Aishah Hassan, Yusni Mohamad Yusop

To Link this Article: http://dx.doi.org/10.6007/IJARBSS/v11-i8/10616 DOI:10.6007/IJARBSS/v11-i8/10616

Received: 11 June 2021, Revised: 18 July 2021, Accepted: 10 August 2021

Published Online: 25 August 2021

In-Text Citation: (Tanni et al., 2021)

To Cite this Article: Tanni, K. T., Zainudin, Z. N., Hassan, S. A., \& Yusop, Y. M. (2021). The Relationship between Emotional Regulation and Depression among Adolescent in Bangladesh. International Journal of Academic Research in Business and Social Sciences, 11(8), 1911-1925.

Copyright: @ 2021 The Author(s)

Published by Human Resource Management Academic Research Society (www.hrmars.com)

This article is published under the Creative Commons Attribution (CC BY 4.0) license. Anyone may reproduce, distribute, translate and create derivative works of this article (for both commercial and non-commercial purposes), subject to full attribution to the original publication and authors. The full terms of this license may be seen

at: http://creativecommons.org/licences/by/4.0/legalcode

Vol. 11, No. 8, 2021, Pg. 1911 - 1925

http://hrmars.com/index.php/pages/detail/IJARBSS

JOURNAL HOMEPAGE

Full Terms \& Conditions of access and use can be found at http://hrmars.com/index.php/pages/detail/publication-ethics 


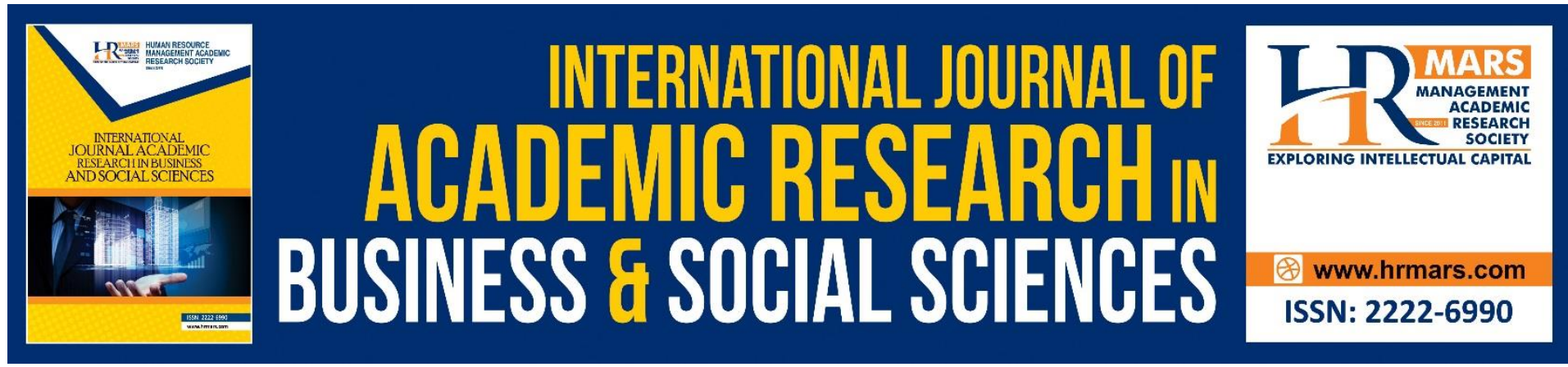

\title{
The Relationship between Emotional Regulation and Depression among Adolescent in Bangladesh
}

\author{
Tanni K. T., Zaida Nor Zainudin, Siti Aishah Hassan, Yusni \\ Mohamad Yusop
}

Faculty of Educational Studies, University Putra Malaysia, Serdang Selangor. Malaysia Email: toncoun_44@yahoo.com, zaidanor@upm.edu.my, sitiaishahh@upm.edu.my, yusni_my@upm.edu.my

\begin{abstract}
Depression is a major public health issue both in Bangladesh and in the world and should be given more focus, in particular to the identification of prevention and intervention targets. The research aimed at researching relationships between the strategy of emotional regulation and adolescent depression. This quantitative study chose the youth population in Dhaka City, Bangladesh. The researcher selected the participants randomly from among those in the 7th to 10 th grades. A class with 40 participants was selected. The researcher sent questionnaires to the participants and obtained their responses to the questionnaires. The data from this study were used to examine the relationship between emotional control and depression in adolescents in Bangladesh by using the Spearman correlation analysis. The findings show that the relationships between emotional regulation and depression, higher extents of 'suppression-focused' emotional regulation styles appear to be related to the reporting of more borderline clinical depression, while more cognitive 'reappraisal-focused' styles are not significantly associated with the symptoms of depression. The outcomes concerning the connections between cognitive strategies for emotional regulation and depression may serve as potential targets for a mental health intervention for adolescents in developing countries. This study outcome will also contribute to the adolescent crisis intervention strategy among adolescent in Bangladesh. In the individual and group treatment sessions, the therapists may use a strategy plan for adaptive emotional regulations to prevent depression.
\end{abstract}

Keyword: Depression, Suppression, Cognitive Reappraisal, Adolescent

\section{Introduction}

Major depressive disorder (MDD) is a highly impedimentary mental disorder, classified by the World Health Organization (Mathers, 2008) as the world's third most disabling health problem and the most debilitating psychological illness. MDD is characterized by the DSM-5 as an affective disorder of chronic nature marked by an extreme sadness and the inability to experience pleasure (AP, 2013). With a prevalence of about $1 \%, M D D$ is relatively rare among children (Birmaher et al., 1996), but its incidence increases considerably to $10.5 \%$ during 
adolescence (Balázs et al., 2013) with a lifetime prevalence of up to $25 \%$ at the end of this developmental period (Kessler et al., 2001).

Depression in adolescents is also a common disorder. Overall lifetime prevalence in mixed samples of children and adolescents ranges from 3.7 percent (age 8 - 15; Merikangas et al., 2010a) to 11.8 percent (age 13 - 18; Merikangas et al., 2010b) with varying rates of gender and age (i.e., lifetime prevalence rates for older teens and women). The average starting age is estimated between 11 and 14 years in longitudinal on community samples adolescents with increasing incidence rates during adolescence development (Merikangas et al., 2009). In adolescents, the depression phenomenology and course normally coincide remarkably with adults, but with significant variations in development in terms of memory, self and social knowledge, actions and stress, and emotional control (Blakemore, 2008). Depression in adolescents is frequently persistent, and the chances of relationship problems, academic problems, legal issues, and suicidal attempts and trials (Stice et al., 2009) are known to increase. Lifetime prevalence is estimated at 8.7 percent (Merikangas et al., 2010) in adolescents who have serious disability from depression. Depression is a significant public health problem impacting life quality, mortality, and morbidity (Kessler \& Bromet, 2013). The global burden of disease is expected to hit about $15 \%$ by December 2020 (Murray \& Lopez, 1996). Bowlby (1980) states that depression is associated with perceived helplessness in building and maintaining relationships, which have been developed from negative early care experiences that contribute to the creation of internal work models that consider one to be unlovable and unworthy (Cummings \& Cicchetti, 1990). In accordance with Bowlby (1980), the negative viewpoints, i.e., conceptual representation of potential scenarios, which are similarly assisted by pessimistic template, Roepke and Seligman (2015) reported the primary causal variable in the creation and maintenance of a depression. These points lead to the essential results of Beck on cognitive distortions (Beck, 1963).

Regulation of emotion refers to policies and processes that influence or alter emotional experience or expression. This deals with the modulation of both positive and negative emotions (Gross \& Thompson, 2007). Emotional regulatory processes can either be automatic, controlled or aware or unaware (Gross 1998). They can be designed to change current or anticipated emotions regarding intensity, quality, speed of recovery and duration in order to adapt to a situation (Thompson, 1994). The emotion regulation process model also includes the selection of circumstances, changes to the situation, careful deployment, cognitive shift, and reaction control (Gross, 1998). Emotion control requires the ability to control one's emotions on the basis of many different abilities (Thompson, 1994). Past studies have indicated that emotional difficulties may lead to a greater risk for psychopathological integration, such as anxiety and depressive disorders (Steinberg \& Avenevoli, 2000; Steinberg et al., 2006). Nonetheless, the processes of emotion-regulation can increase or decline emotional reaction (see Berking et al., 2013; Hofmann et al., 2012). Specific emotion-related measures may also vary in their efficacy to decrease high negative effects and increase the positive impact that are common to anxiety and depression, i.e., those that change the severity and form of emotions (Campbell-Sills et al., 2006), internalizing psychopathology among adolescents (Berking et al. 2013; Hofmann et al., 2012). Certain strategies to represent cognitive emotion, such as rumination and worry, probably initiate a superb process known as repetitive negative thinking (Fresco et al., 2002; McEvoy et al., 2013; Tanni et. al, 2021). Deficits in emotional experience and spontaneity can be as maladaptive as failings in emotional avoidance (Cole et al., 1994), in adaptive regulation, emotional experience, in 
addition to modification, are monitored, evaluated, and emphasized in order to make the most of the emotional disorder (Thompson \& Calkins, 1996).

Gross (2002) examined two strategies of emotional regulation: Suppression and cognitive reappraisal. The cognitive reappraisal is usually superior to the suppression, as the suppression decreases the negative but non-experience of feelings and decreases positive emotional expression and experience. In addition to the suppression, our negative feelings do not only decrease, but it also increases our organism's pleasant behavior. The results even show that the suppression makes people less emotive, and therefore, less social support for people. In social relations, it even has important effects (John \& Gross, 2003). Therefore, emotional control attempts can increase the danger of dysregulation of emotions. Cole et al. (1994) stresses the importance of emotive responses acceptance and appreciation, because the tendency to have negative emotions responding to one's emotional responses is ill adjustable and is connected to greater emotional regulation difficulties.

Emotion control requires extrinsic and intrinsic mechanisms responsible for tracking, analyzing, and altering emotional responses in order to achieve one's objectives (Thompson, 1994). The capacity to adapt with aversive feelings effectively arguably helps retain a sense of balance in distressing conditions that are believed to interfere with the processing of stressed genetic information (Teasdale \& Barnard, 1993). Efficient emotion control abilities can also be argued to help prevent, decrease or shorten the severity or the duration of dysphonic states (Berking, Ebert, Cuijpers, \& Hofmann, 2013) that have been shown to reactivate depressed thought patterns (Jarrett et al., 2012; Segal et al., 2006), and thereby contribute to the (re-)incidence of depression. The findings of longitudinal studies indicate that emotion control deficits predict the subsequent seriousness of symptoms of depression. For example, experiments using ecological momentary found that the negative effect on individuals meeting MDD requirements lasted longer than on non-clinical samples, due to aversive living (Peeters et al., 2003). Despite their clinical importance for the development and maintenance of clinical difficulties, Gratz and Roemer (2004) state that in adolescents, the role of alteration in emotional regulation has not been properly studied. However, interest in this issue has been growing in the last few years (Allan et al., 2015; Campbell-Sills and Barlow 2007; Compare et al., 2014; Malhi et al., 2017; Malik et al., 2015; Nolen-Hoeksema et al., 2008; Tull et al., 2016). Based on the findings of a comprehensive analysis, Joormann and Stanton (2016) conclude that depressed people were more likely to respond with ineffective strategies, such as ruminating and suppression to a negative effect and find it difficult to adopt successful strategies like avoidance and re-evaluation. Ozlem et al. (2017) conclude that cases of depressive symptoms require more regular use of mental maladaptive strategies, such as stopping and ruminating. This research has confirmed the current evidence on the relationship between emotional controls and depression.

Emotional regulation and depression are related problems of mental health. Some findings show that the two mental health issues are interconnected. Joormann and Stanton (2016) show that depressed people are more likely to respond with ineffectual strategies, such as rumination and suppression to negative effects and find it difficult to implement effective approaches, such as distractions and reappraisal. Özlem et al. (2017) state that the use of maladaptive method of emotional regulation, such as suppression and negative thinking, is more common in cases of depressive signatures. However, there have been very few studies conducted on these issues in adolescents. There seems to be very few research in Bangladesh on the relationship between emotional control and depression among young people in Bangladesh. The results of this study may serve as good examples in developing countries, 
such as Bangladesh, on the connection of emotional regulation and depression. This study extends the scope of previous studies that examined the association between emotional regulation and depression by explaining the two emotion regulation strategies (cognitive reappraisal and suppression) that are likely to play a role in increasing vulnerability to depression. We predicted that depression is related not only to more frequent use of suppression, but also to less frequent use of cognitive reappraisal. Besides that, it was assumed that depression is related to more frequent use of maladaptive emotion regulation strategies, specifically depression, and to a less frequent use of cognitive reappraisal. The purpose of the present study was to investigate the relationship between suppression(ER) and depression among adolescent. Beside that this study also investigated the relationship between cognitive reappraisal and depression.

\section{Methodology}

This quantitative study chose the youth population in Dhaka City, Bangladesh. Bangladesh is a country in Asia. There are 64 districts in Bangladesh and Dhaka is the capital city of Bangladesh. The total secondary student in Bangladesh is 585199 (BANBEIS, 2018). This study's target population is the adolescent student in Dhaka City, Bangladesh. There are 29 most popular high schools in Dhaka city. There are 20 high-ranking schools in this 29 school. In addition, in this 20 school 15 schools have counseling support unit. The randomized sampling applied in this study following lottery to select one higher secondary schools from this 15 higher secondary school of Dhaka city in Bangladesh. After selecting the school, researcher chose 7th to 10th grade class randomly. In Bangladesh all school's classes are separated for girls and boys. One class with 40 participants was selected. The researcher sent the questionnaires to the participants and obtained their responses to the questionnaires. The data from this study were used to examine the relationship between emotional control and depression in adolescents in Bangladesh by using the Spearman correlation analysis. This study used Beck's Depression Inventory- BDI-II (1996) to measure depression. The Internal consistency found for the BDI ranges from .73 to .92 and mean was .86. (Beck, Steer, \& Garbin, 1988). The BDI establishes high internal consistency, with alpha coefficients of .86 and .81 for psychiatric and non-psychiatric populations respectively (Beck et al., 1988). To measure the suppression (ER) and cognitive appraisal (ER), the researcher used Emotion Regulation Questionnaire (Gross \& John, 2003). Alpha reliabilities averaged .79 for Reappraisal and .73 for Suppression. Test-retest reliability across 3 months was .69 for both scales.

\section{Findings and Discussion Demography}

A total of 40 subjects were involved in this study. They were adolescents ranging from 10 to 15 years old, 20 males and 20 females. They studied in class nine in the selected school. All participants selected from school are from urban society. Table 1 shows that according to age, 31 respondents ( $77.5 \%$ ) were from 10 to 12 years old, and 9 respondents ( $22.5 \%)$ were in the range of 13 to 15 years old.

Table 1. Age of respondents

\begin{tabular}{ccccc}
\hline & S.N.O & Age & Frequency & Scores in \% \\
\hline & 1 & $10-12$ & 31 & 77.5 \\
& 2 & $13-15$ & 09 & 22.5 \\
\hline Total & & & 40 & 100 \\
\hline
\end{tabular}


In this study, the Emotion Regulation Questionnaire (Gross \& John, 2003) was used to assess suppression (ER) and cognitive appraisal (ER). The descriptive statistics (mean, standard deviation, minimum and maximum) were computed on emotional regulation. The results are presented in Table 2 . The scores were obtained from the sample ranging from the minimum of the suppression scores that is 8 , while the maximum of the suppression scores is 15 with a mean score of 11.08 and standard deviation of 1.639. Consequently, the scores were obtained from the sample ranging from the minimum of the cognitive appraisal scores that is 21 and the maximum is 27 with a mean score of 23.32 and SD of 1.607.

On the other hand, Beck's Depression Inventory-BDI-II (1996) was used to measure depression. The descriptive statistics (mean, standard deviation, minimum and maximum) were computed on Depression. The result is presented in Table 2. The scores were obtained from the sample ranging from the minimum of the depression scores that is 11 and the maximum is 20 with the mean score of 15.33 and SD of 2.615 .

Table 2: Mean scores and standard deviation of Suppression, Cog Reappraisal and Depression

\begin{tabular}{llllll}
\hline & N & Minimum & Maximum & Mean & SD \\
\hline Suppression & 40 & 08 & 15 & 11.08 & 1.639 \\
$\begin{array}{l}\text { Cog } \\
\text { Reappraisal }\end{array}$ & 40 & 21 & 27 & 23.32 & 1.607 \\
Depression & 40 & 11 & 20 & 15.33 & 2.615 \\
\hline
\end{tabular}

\section{Relationship between suppression(ER) and depression among adolescent}

The study examined at the relationship between emotional regulations and depression and found that the correlation between suppression and depressive symptoms is significant. There is a strong relationship between suppression (ER) and depression, according to the Spearman correlation analysis. To measure the relationship between emotional regulation and depression, the Spearman correlation analysis was conducted. The results of the correlation analysis shown in Table 3 reveal that depression has a significant high correlation with suppression emotional regulation $(\rho=.766, p=.000)$. More specifically, adolescents who used suppression experienced less positive emotion, which is correlated with depressive symptoms.

Table 3: Spearman correlation between Emotional regulation (suppression) and Depression

\begin{tabular}{ccccc}
\hline & & Suppression & Depression \\
\hline Spearman Rho & Suppression(ER) & Correlation & 1.000 & $.766^{* *}$ \\
& & & \\
& Coefficient & & .000 \\
& Sig.(2 tailed) & & 40 \\
\hline & $\mathrm{N}$ & $.766^{* *}$ & 1.000 \\
& Copression & Correlation & & \\
& Coefficient & .000 & \\
& Sig.(2 tailed) & 40 & \\
& $\mathrm{~N}$ & & \\
& & & \\
& &
\end{tabular}

** Correlation is significant at the 0.01 level (2-tailed). 
These findings are supported by the findings of previous studies that suppression has a relationship with clinical depression in both undergraduates with small to modest effect sizes (d's = 0.35 - 0.71) (e.g., Aldao \& Dixon-Gordon, 2014; Boden \& Thompson, 2015; del PalacioGonzalez,Berntsen, \& Watson, 2017; Gross \& John, 2003; Haga et al., 2009; McLean et al., 2007; Moore et al., 2008; Richmond, Hasking, \& Meaney, 2017; Tran \& Rimes, 2017). Joormann and Gotlib (2010) and Forkmann et al. (2014a; 2014b) have also found that the suppression of depressing symptoms $(d=0.43)$ is also associated with suppressive symptoms that are a strong predictor of the severity of depression among depressed disorders patients (but no cognitive reappraisal). The experience of depression may lead to important changes in cognitive and biological processes, or scarring, which in turn fuels increased rumination persisting beyond the offset of the disorder. However, our finding is consistent with a growing literature supporting that adolescents' suppressive emotion serves as an indicator for a vulnerability factor, which is associated with increased risk for subsequent increases in depression (Abela et al., 2012; Hankin, 2009; Hilt et al., 2010). On the contrary, another study reveals that expressive suppression is not associated with increased severity of depression or anxiety symptoms. The study examined a clinical sample of individuals with SAD who on average were elevated in suppression. However, the relatively small SAD group size prevented the detection of an association with symptom (D'Avanzato et al., 2013). There is a major impact when examining suppression for the regulation of negative emotions in daily, autonomous memories. Individuals with a high level of depression support a higher suppression than those with a low level of depression $(d=1.44$; del Palacio-Gonzalez et al., 2017). Depression is more strongly associated with suppression in positive emotions (i.e., happiness) (Zhou, Shang, \& Wang, 2016).)

\section{Relationship between Cognitive Appraisal and Depression}

Similarly, to identify the correlation between Depression and Cog Reappraisal, a Spearman correlation coefficient test was executed. The Spearman correlation analysis explained that the value of $\rho=.536$ and $p=.101>.05$, is bigger than the alpha level. These findings revealed in Table 4 show that there is no significant relationship between cognitive appraisal and depression. Previous literature states that controlling strong emotions and reappraisal can become more cognitively taxing, and therefore, harder to be enforced effectively (Sheppes et al., 2011). Cognitive reappraisal has proven to be less associated with psychopathology symptoms (Aldao et al., 2010), and there have not been any reductions in research in clinical sample reassessment ability (e.g., Aldao \& Mennin, 2012). The reappraisal implications may be more susceptible to contextual and other characteristics, and so it may be premature to assume that reassessment issues do not define persons remitted. It is obvious that more research is needed on the stability of emotional control strategies. 
Table 4: Spearman correlation between depression and cog reappraisal

\begin{tabular}{cllcc}
\hline & & Depression & Cog Reappraisal \\
\hline Spearman Rho & Suppression(ER & Correlation & 1.000 & .101 \\
& Coefficient & & \\
& Sig.(2 tailed) & & .536 \\
& $\mathrm{~N}$ & & 40 \\
\hline & Copression & Correlation & .101 & 1.000 \\
& Coefficient & & \\
& Sig.(2 tailed) & .536 & \\
& $\mathrm{~N}$ & 40 & \\
\hline
\end{tabular}

\section{Discussion}

Some of the previous studies illustrate that cognitive reappraisal has been found to be positively associated with indicators of health and well-being, whereas expressive suppression was found to be negatively related to health and well-being (Gross \& John, 2003). Liverant et al. (2008) reported that a cognitive reappraisal is effective to minimize sadness for moderate to severely affected individuals. Similarly, another evidence indicates that individuals' diversity in strategies used across a variety of circumstances, or their emotion control versatility, may be important to remember, with individuals drawing from various strategies across different situations shown to exhibit lower symptom levels (Aldao \& NolenHoeksema, 2012b). Joormann and Gotlib (2010) have shown that suppression problems are present to a greater extent in moderately depressed patients, and depression is also associated with less frequent use of reappraisal. Depressed people reported using cognitive reappraisal substantially, but less frequently than participants who were socially anxious (D'Avanzato et al., 2013). Eftekhari et al. (2009) have established that both suppression and cognitive reappraisal are correlated with depressed symptom severity in their studies, while the people of reappraisal and low suppression have reported the lowest levels of symptoms among the groups under study, and those with high levels of the use of the two strategies reported effective ER and relatively little symptoms of depression.

An exception to this is a study by Aldao and Nolen-Hoeksema (2010) that investigated the relationship between rumination, repression of the mind, and re-evaluation with symptoms of depression, anxiety, and eating disorder. All three strategies for emotion management are significantly recognized by a latent factor in cognitive emotion control that is significantly correlated with the symptoms of all three disorders. However, this research was constrained by the use, for clinical populations, of an undiagnosed college sample, and as such the findings from this study cannot be generalized. It is also likely that adaptive techniques, such as reappraisal, are hard to be adopted by professional groups, and thus a lesser association between review usage and severity of the symptoms can occur.

Such results are repeated in many previous studies (Aldao \& Nolen-Hoeksema, 2010; Aldao \& Nolen-Hoeksema, 2012a) and one interpretation is that this might indicate that depressive symptoms are related to successful re-appraisal (Aldao et al. (2010). In keeping with this notion, Sheppes et al. (2011) have shown that re-evaluation can become more fiscal and less useful, as is common in the context of emotional disorders, if individuals' control is extreme 
emotionally. The differences between depressed and non-depressed people have also been reported and are related to less successful emotional regulation of the negative influence in neural correlates with cognitive reappraisal (Johnstone et al., 2007; Siegle et al., 2007).

This study demonstrates how emotional control and depression can be linked in adolescents in Bangladesh. This offers potential targets for mental health improvement interventions. However, further work is needed because it was the initial study that focused on these relationships across adolescents in Bangladesh. In order to support young people in changing their cognitive styles from suppression to cognitive evaluation, intervention should also be developed. The findings also support the conclusion that more depression is observed in people using maladaptive cognitive strategies like suppression and less psychopathology is observed in people using more adaptive strategies like positive re-appraisal (Garnefski \& Kraaij, 2006). More specifically, the results show that the more suppressive emotional regulation linked to the more depressive symptoms. In addition, a 'Reappraisal-focused' style (including Positive reappraisal, Positive refocusing, Planning and Putting into Perspective) was found to not have any significant relationship with the reporting of less depressive symptoms. These results fit in partially with the findings of previous studies, where similar relationships were found in various groups (ranging from early adolescents to elderly) (Garnefski \& Kraaij, 2006). In addition, the result shows that the specific predicting depression strategies in a developing country like Bangladesh do not differ from the predicting depression strategies in economically more developed countries. This underlines the universal importance of cognitive emotion regulation strategies as associated factors of depression.

\section{Implications of the Study}

The results of this study provide suggestions for developing an intervention plan to improve mental health condition of adolescents. Previous studies confirm a universal benefit of interventions that focus on changing maladaptive emotion regulation (Fresco et al., 2013). They show that in a country like Bangladesh, just like in other countries, targets for prevention and intervention of psychopathology could be found in changing maladaptive cognitive strategies like rumination, catastrophizing, and self-blame into more adaptive strategies like positive reappraisal. Focusing such interventions on adolescents at an early age may reduce the risks of developing depression during adulthood (Wittchen et al., 2014). The present study found indications of the relationships between emotional regulation and depression in adolescents in Bangladesh. This study outcome will also contribute to the adolescent crisis intervention strategy. In the individual and group treatment sessions, the therapists may use a strategy plan for adaptive emotional regulations to prevent depression. Extensive study is necessary to provide concrete evidence of co-morbidity. However, because this is the first study that focuses on such relationships in Bangladesh, further research is necessary. If the results can be confirmed, interventions should be developed to help adolescents change their cognitive styles from suppression to reappraisal and minimize depressive symptoms.

\section{Limitations and Future Direction}

There are some limitations of the study that should be mentioned. First of all, the research was conducted among participants at a single institution in Bangladesh. Therefore, no conclusion can be drawn on causality. Secondly, the results of the present study were based on self-reported data, which may limit the validity of the results. Thirdly, this study relied on self-report measures of the frequency of strategy use. There are many challenges in assessing the dispositional use of emotion regulation strategies, such as limitations in individuals' 
awareness and ability to report accurately on their daily strategy use. Therefore, it cannot be explained confidently that the participants' self-reported use of emotion regulation strategies corresponds to the characteristics of their actual use of these strategies in their daily life. In addition, it has been argued that single emotion regulation strategies are not likely to be universally adaptive or maladaptive, but that a person's ability to select strategies, which appropriately fit a situation at hand and to flexibly draw from a wide variety of strategies are more important indicators of adaptive emotion regulation (e.g. Hofmann et al., 2012). An experience sampling approach would allow investigation of these variables as well as ensuring greater generalizability of the results to participants' day to day lives. In addition, given that the present study is cross-sectional and did not include laboratory measures, which assess diagnostic group differences in the deployment and effectiveness of each strategy, this limits our ability to draw the specific conclusions. However, self-reported use of these strategies has been found in recent studies to be related to other laboratory measures of emotion regulation, including psychophysiological measures of stress response (e.g., Mauss et al., 2007) and recently, to enhance reappraisal ability (McRae et al., 2012). Further research should consider the cultural issues as the present study was conducted in a single cultural context. Future studies should, therefore, further investigate the cultural effect and use other data-assembly methods like interviews and include prospective elements to obtain more reliable findings.

\section{Conclusion}

The current research aimed to expand past results by studying directly the non-clinical adolescent samples to find out the specific relation between emotional regulation and depressive symptoms. In this study, 'suppression' has been shown to be the focused emotional styles of regulation that are highly related to clinical depression. On the other hand, cognitive reappraisal styles are not significantly linked to depression symptoms. The analysis of the data using the Spearman correlation analysis and the correlation coefficient show a high connection between emotional control and depression. With the advance review, the results of this research reinforce the established literature. Furthermore, the outcomes of emotion regulation and depression relationships may provide possible targets for intervention to improve emotional wellness for adolescents in developing countries. This is because the sample size was small, and as such the result is difficult to be generalized. This research needs to be carried out further on a larger population in order to obtain a clear proof of the relationship between ER and depression among young people in the developing world.

\section{References}

Abela, J. R. Z., Hankin, B. L., Sheshko, D. M., Fishman, M. B., \& Stolow, D. (2012). Multi-wave prospective examination of the stress-reactivity extension of response styles theory of depression in high-risk children and early adolescents. Journal of Abnormal Child Psychology, 40(2), 277-287.

Aldao, A., \& Dixon-Gordon, K. L. (2014). Broadening the scope of research on emotion regulation strategies and psychopathology. Cognitive Behaviour Therapy, 43, 22-33. https://doi.org/10.1080/16506073.2013.816769

Aldao, A., \& Mennin, D. S. (2012). Paradoxical cardiovascular effects of implementing adaptive emotion regulation strategies in generalized anxiety disorder. Behaviour Research and Therapy, 50, 122-130. 
Aldao, A., \& Nolen-Hoeksema, S. (2012). When are adaptive strategies most predictive of psychopathology? Journal of Abnormal Psychology, 121(1), 276-281.

Aldao, A., \& Nolen-Hoeksema, S. (2012a). When are adaptive strategies most predictive of psychopathology? Journal of Abnormal Psychology, 121, 276-281.

Aldao, A., \& Nolen-Hoeksema, S. (2010). Specificity of cognitive emotion regulation strategies: A transdiagnostic examination. Behaviour Research and Therapy, 48, 974-983.

Aldao, A., Nolen-Hoeksema, S., \& Schweizer, S. (2010). Emotionregulation strategies across psychopathology: A meta-analytic review. Clinical Psychology Review, 30, 217-237.

Allan, N. P., Norr, A. M., Macatee, R. J., Gajewska, A., \& Schmidt, N. B. (2015). Interactive effects of anxiety sensitivity and emotion regulation on anxiety symptoms. Journal of Psychopathology and Behavioral Assessment, 37, 663-672. https://doi.org/10.1007/s10862-015-9484-z.Association AP (2013) Major depressive disorder and the "bereavement exclusion". American Psychiatric Publishing, Washington, DC (Retrieved July 24, 2013)

Balázs, J., Miklósi, M., Keresztény, Á., Hoven, C. W., Carli, V., Wasserman, C., ... \& Cotter, P. (2013). Adolescent subthreshold-depression and anxiety: Psychopathology, functional impairment and increased suicide risk. Journal of Child Psychology and Psychiatry, 54(6), 670-677.

Berking, M., Ebert, D., Cuijpers, P., \& Hofmann, S. G. (2013). Emotion regulation skills training enhances the efficacy of inpatient cognitive behavioral therapy for major depressive disorder: a randomized controlled trial. Psychotherapy and Psychosomatics, 82(4), 234245.

Beck, A. T., Steer, R. A., \& Brown, G. K. (1996). Beck depression inventory-II. San Antonio, 78(2), 490-498.

Birmaher, B., Ryan, N. D., Williamson, D. E., Brent, D. A., Kaufman, J., Dahl, R. E., Perel, J., Nelson, B. (1996) Childhood and adolescent depression: A review of the past 10 years. Part I. J Am Acad Child Adolesc Psychiatry, 35(11), 1427-1439.

Blakemore, S. J. (2008). The social brain in adolescence. Nature Reviews Neuroscience, 9(4), 267-277.

Boden, M. T., \& Thompson, R. J. (2015). Facets of emotional awareness and associations with emotion regulation and depression. Emotion, 15, 399-410. https://doi.org/10. 1037/emo0000057.

Bowlby, J. (1980). Attachment and Loss: Loss, sadness, and depression (Vol. 3). New York: Basic Books.

Campbell-Sills, L., Barlow, D. H., Brown, T. A., \& Hofmann, S. G. (2006). Acceptability and suppression of negative emotion in anxiety and mood disorders. Emotion, 6, 587-595.

Campbell-Sills, L., \& Barlow, D. (2007). Incorporating emotion regulation into conceptualizations and treatments of anxiety and mood disorders. In J. Gross (Ed.), Handbook of emotion regulation (pp.542-559). New York: Guilford Press.

Compare, A., Zarbo, C., Shonin, E., Van Gordon, W., \& Marconi, C. (2014). Emotional regulation and depression: A potential mediator between heart and mind. Cardiovascular Psychiatry and Neurology, 1-10. https://doi.org/10.1155/2014/324374.

Cole, P. M., Martin, S. E., \& Dennis, T. A. (2004). Emotion regulation as a scientific construct: Challenges and directions for child development research. Child Development, 75, 317333. 
Cuijpers P., de Graaf R., van Dorsselaer S. (2004). Minor depression: Risk profiles, functional disability, health care use and risk of developing major depression. J Affect Disord, 79(1), 71-79.

Cummings, E. M., \& Cicchetti, D. (1990). Toward a transactional model of relations between attachment and depression. In M. T. Greenberg, D. Cicchetti \& E. M. Cummin (Eds.), Attachment in the preschool years (pp. 339-372). Chicago: University of Chicago Press.

Del Palacio-Gonzalez, A., Berntsen, D., \& Watson, L. A. (2017). Emotional intensity and emotion regulation in response to autobiographical memories during dysphoria. Cognitive Therapy and Research, 41, 530-542. https://doi.org/10.1007/s10608-0179841-1

D’Avanzato, C., Joormann, J., Siemer, M., \& Gotlib, I. H. (2013). Emotion regulation in depression and anxiety: Examining diagnostic specificity and stability of strategy use. Cognitive Therapy and Research, 37(5), 968-980.

Fresco, D. M., Frankel, A. N., Mennin, D. S., Turk, C. L., \& Heimberg, R. G. (2002). Distinct and overlapping features of rumination and worry: The relationship of cognitive production to negative affective states. Cognitive Therapy and Research, 26, 179-188.

Fresco, D. M., Mennin D. S., Heimberg, R. G., Ritter, M. (2013) Emotion Regulation Therapy for Generalized Anxiety Disorder. Cogn Behav Pract, 20, 282-300. Link: https://goo.gl/RzBjmR

Forkmann, T., Scherer, A., Böcker, M., Pawelzik, M., Gauggel, S., \& Glaesmer, H. (2014a). The relation of cognitive reappraisal and expressive suppression to suicidal ideation and suicidal desire. Suicide and Life-threatening Behavior, 44, 524-536. https://doi. org/10.1111/sltb.12076.

Forkmann, T., Scherer, A., Pawelzik, M., Mainz, V., Drueke, B., Boecker, M., \& Gauggel, S.(2014b). Does cognitive behavior therapy alter emotion regulation in inpatients with a depressive disorder? Psychology Research and Behavior Management, 7, 147153.https://doi.org/10.2147/prbm.s59421

Gratz, K. L., \& Roemer, L. (2004). Multidimensional Assessment of Emotion Regulation and Dysregulation: Development, Factor Structure, and Initial Validation of the Difficulties in Emotion Regulation Scale. Journal of Psychopathology and Behavioral Assessment, 26(1), 41-54.

Gross, J. J., \& John, O. P. (2003). Individual differences in two emotion regulation processes: Implications for affect, relationships, and well-being. Journal of Personality and Social Psychology, 85, 348-362. https://doi.org/10.1037/0022-3514.85.2.348.

Gross, J. J., \& Thompson, R. A. (2007). Emotion regulation: Conceptual foundations. In J. J. Gross (Ed.), Handbook of emotion regulation (pp. 3-24). New York, NY: Guilford Press.

Gross J. J. (2002). Emotion regulation: Affective, cognitive, and social consequences. Psychophysiology, 39, 281-291. 10.1017/S0048577201393198 [PubMed] [CrossRef] [Google Scholar]

Gross, J. J. (1998). The emerging field of emotion regulation: an integrative review. Review of General Psychology, 2, 271-299. doi:10.1037/1089-2680.2.3.271.

Garnefski, N., \& Kraaij, V. (2006). Relationships between cognitive emotion regulation strategies and depressive symptoms: A comparative study of have specific samples. Personality and Individual Differences, 40, 1659-1669. https://goo.gl/TkhwAQ

Haga, S. M., Kraft, P., \& Corby, E. (2009). Emotion regulation: Antecedents and wellbeing outcomes of cognitive reappraisal and expressive suppression in cross-cultural samples. 
Journal of Happiness Studies, 10, 271-291. https://doi.org/10.1007/s10902-007-90803.

Hankin, B. L. (2009). Development of sex differences in depressive and co-occurring anxious symptoms during adolescence: Descriptive trajectories and potential explanations in a multiwave prospective study. Journal of Clinical Child and Adolescent Psychology, 38(4), 460-472.

Hilt, L. M., Armstrong, J. M., \& Essex, M. J. (2012). Early family context and development of adolescent ruminative style: Moderation by temperament. Cognition and Emotion, 26(5), 916-926.

Hofmann, S. G., Sawyer, A. T., Fang, A., \& Asnaani, A. (2012). Emotion dysregulation model of mood and anxiety disorders. Depression and Anxiety, 29(5), 409-416.

Johnstone, T., van Reekum, C. M., Urry, H. L., Kalin, N. H., \& Davidson, R. J. (2007). Failure to regulate: Counterproductive recruitment of top-down prefrontal-subcortical circuitry in major depression. Journal of Neuroscience, 27(33), 8877-8884.

Joormann, J., \& Stanton, C. (2016). Examining emotion regulation in depression: A review and future directions. Behaviour Research and Therapy, 86, 35-49. https://doi.org/10.1016/j.brat.2016.07.007.

Joormann, J., \& Gotlib, I. H. (2010). Emotion regulation in depression: Relation to cognitive inhibition. Cognition and Emotion, 24, 281-298. https://doi.org/10.1080/02699930903407948.

Kessler, R. C., Avenevoli, S., Merikangas, K. R. (2001). Mood disorders in children and adolescents: An epidemiologic perspective. Biol Psychiatry, 49(12),1002-1014

Kessler, R. C., \& Bromet, E. J. (2013). The epidemiology of depression across cultures. Annual Review of Public Health, 34, 119-138.

Mathers, C. (2008). The global burden of disease: 2004 update. World Health Organization, Geneva.

Liverant, G. I., Brown, T. A., Barlow, D. H., \& Roemer, L. (2008). Emotion regulation in unipolar depression: The effects of acceptance and suppression of subjective emotional experience on the intensity and duration of sadness and negative affect. Behaviour Research and Therapy, 46, 1201-1209. http://dx.doi.org/10.1016/j.brat.2008.08.001.

Malik, S., Wells, A., \& Wittkowski, A. (2015). Emotion regulation as a mediator in the relationship between attachment and depressive symptomatology: A systematic review. Journal of Affective Disorders, 172, 428-444. https://doi.org/10.1016/j.jad.2014.10.007

Malhi, G., Byrow, Y., Outhred, T., Das, P., \& Fritz, K. (2017). Irritability and internalizing symptoms: Modeling the mediating role of emotion regulation. Journal of Affective Disorders, 211, 144-149. https://doi.org/10.1016/j.jad.2016.12.021

McRae, K., Jacobs, S. E., Ray, R. D., John, O. P., \& Gross, J. J. (2012). Individual differences in reappraisal ability: Links to reappraisal frequency, well-being, and cognitive control. Journal of Research in Personality, 46(1), 2-7.

McEvoy, P. M., Mahoney, A. E., \& Moulds, M. L. (2010). Are worry, rumination, and post-event processing one and the same? Development of the Repetitive Thinking Questionnaire. Journal of Anxiety Disorders, 24(5), 509-519.

McEvoy, P. M., Watson, H., Watkins, E. R., \& Nathan, P. (2013). The relationship between worry, rumination, and comorbidity: Evidence for repetitive negative thinking as a transdiagnostic construct. Journal of Affective Disorders, 151(1), 313-320. 
McLean, C. P., Miller, N. A., \& Hope, D. A. (2007). Mediating social anxiety and disordered eating: The role of expressive suppression. Eating Disorders: The Journal of Treatment \& Prevention, 15, 41-54. https://doi.org/10.1080/10640260601044485.

Merikangas, K. R., He, J. P., Brody, D., Fisher, P. W., Bourdon, K., \& Koretz, D. S. (2010a). Prevalence and treatment of mental disorders among US children in the 2001-2004 NHANES. Pediatrics, 125(1), 75-81.

Merikangas, K. R., Nakamura, B. A., \& Kessler, R. C. (2009). Epidemiology of mental disorders in children and adolescents. Dialogues in Clinical Neuroscience, 11(1), 7-20.

Moore, S. A., Zoellner, L. A., \& Mollenholt, N. (2008). Are expressive suppression and cognitive reappraisal associated with stress-related symptoms? Behaviour Research and Therapy, 46, 993-1000. https://doi.org/10.1016/j.brat.2008.05.001.

Murray, C. J. L., \& Lopez, A. D. (Eds.). (1996). The Global Burden of Disease: A Comprehensive Assessment of Mortality and Disability from Diseases, Injuries, and Risk Factors in 1990 and Projected to 2020. Cambridge, MA: Harvard Univ. Press.

Nolen-Hoeksema, S., Wisco, B., \& Lyubomirsky, S. (2008). Rethinking rumination. Perspectives on Psychological Science, 3, 400-424. https://doi.org/10.1016/j.jad.2016.12.021

Özlem, J., Naumann, E., Holmes, E., Tuschen-Caffier, B., \& Samson, A. (2017). Emotion regulation strategies in depressive and anxiety symptoms in youth: $A$ meta-analytic review. Journal of Youth and Adolescence, 46, 261-276. https://doi.org/10.1007/s10964-016-0585-0

Peeters, F., Nicolson, N. A., Berkhof, J., Delespaul, P., \& de Vries, M. (2003). Effects of daily events on mood states in major depressive disorder. Journal of Abnormal Psychology, 112, 203e211. http://dx.doi.org/10.1037/0021-843X.112.2.203

Richmond, S., Hasking, P., \& Meaney, R. (2017). Psychological distress and non-suicidal selfinjury: The mediating roles of rumination, cognitive reappraisal, and expressive suppression. Archives of Suicide Research, 21, 62-72. https://doi.org/10.1080/13811118.2015.1008160.

Roepke, A. M., \& Seligman, M. E. P. (2015). Depression and prospection. British Journal of Clinical Psychology. doi: 10.1111/bjc.12087

Segal, Z. V., Kennedy, S., Gemar, M., Hood, K., Pedersen, R., \& Buis, T. (2006). Cognitive reactivity to sad mood provocation and the prediction of depressive relapse. Archives of General Psychiatry, 63, 749-755. http://dx.doi.org/10.1001/archpsyc.63.7.749.

Siegle, G. J., Ghinassi, F., \& Thase, M. E. (2007). Neurobehavioral therapies in the 21st century: Summary of an emerging field and an extended example of cognitive control training for depression. Cognitive Therapy Research, 31(2), 235-262.

Sheppes, G., Scheibe, S., Suri, G., \& Gross, J. J. (2011). Emotion regulation choice. Psychological Science, 22(11), 1391-13.

Steinberg, L., \& Avenevoli, S. (2000). The role of context in the development of psychopathology: A conceptual framework and some speculative propositions. Child Development, 71, 66-74.

Steinberg, L., Dahl, R., Keating, D., Kupfer, D. J., Masten, A. S., \& Pine, D. (2006). The study of developmental psychopathology in adolescence: Integrating affective neuroscience with the study of context. In D. Cicchetti \& D. Cohen (Eds.), Handbook of developmental psychopathology (2nd ed., pp. 710-741). Hoboken, NJ: Wiley.

Stice, E., Shaw, H., Bohon, C., Marti, C. N., \& Rohde, P. (2009). A meta-analytic review of depression prevention programs for children and adolescents: factors that predict 
magnitude of intervention effects. Journal of Consulting and Clinical Psychology, 77(3), 486.

Tanni, K. T., Zainudin, Z. N., Hassan, S. A., \& Yusop, Y. M. (2021). A Systematic Literature Review on the Influential Family Factors and Cultural Differences in Parent-Adolescent Conflict among Adolescents. International Journal of Academic Research in Business and Social Sciences, 11(5), 405-426.

Teasdale, J. D., \& Barnard, P. J. (1993). Affect, cognition, and change: Remodeling + depressive thought. Hove, U.K.: Lawrence Erlbaum Associates.

Thompson, R. A. (1994). Emotion regulation: A theme in search of definition. Monographs of the Society for Research in Child Development, 59, 25-52. doi:10.1111/j.15405834.1994.tb01276.x.

Thompson, R., \& Calkins, S. (1996). The double-edged sword: Emotional regulation for children at risk. Development and Psychopathology, 8, 163-182.

Tran, L., \& Rimes, K. A. (2017). Unhealthy perfectionism, negative beliefs about emotions, emotional suppression, and depression in students: A mediational analysis. Personality and Individual Differences, 110, 144-147. https://doi.org/10.1016/j.paid. 2017.01 .042

Tull, M., Gratz, K., McDermott, M., Bordieri, M., Daughters, S., \& Lejuez, C. (2016). The role of emotion regulation difficulties in the relation between PTSD symptoms and the learned association between trauma-related and cocaine cues. Substance Use \& Misuse, 51, 1318-1329. https://doi.org/10.3109/10826084.2016.1168445.

Zhou, T., Shang, Z., \& Wang, D. (2016). Emotion suppression in multiple social contexts and its effects on psychosocial functioning: An investigation with Chinese samples. Asian Journal of Social Psychology, 19, 311-324. https://doi.org/10.1111/ajsp.12149. 